\title{
Psychometric properties and factorial structure of the Spanish version of the Children's Beliefs About Parental Divorce Scale (CBAPS)
}

\author{
Mireia Orgilés ${ }^{1}$, María D. Samper ${ }^{2}$, Iván Fernández-Martínez ${ }^{1}$, Juan C. Marzo ${ }^{1}$ and José P. Espada ${ }^{1}$ \\ ${ }^{1}$ Miguel Hernández University, Alicante, Spain \\ ${ }^{2}$ Centro de Salud Mental Infantil de Alicante Benalúa, Alicante, Spain
}

\begin{abstract}
The purpose of this study was to examine for the first time the factor structure and psychometric properties of the Children's Beliefs About Parental Divorce Scale (CBAPS) in a community Spanish-speaking sample. Participants were 341 Spanish children and adolescents aged 10-17 years. Item analysis and exploratory and confirmatory factor analysis suggested an 18-item shortened version of the scale, maintaining the same six subscales as the original measure. Internal consistency was acceptable $(\alpha=.78)$ and convergent validity was supported through correlation between CBAPS and a measure of depression. Gender and age effects on CBAPS scores were found. Overall, the shortened version of the CBAPS obtained was shown to have good psychometric properties for use with Spanish children and adolescents to assess problematic beliefs regarding their parents' divorce.
\end{abstract}

Keywords: problematic beliefs; parental divorce; children; adolescents; depression; assessment

Resumen: Propiedades psicométricas y estructura factorial de la versión española de la Escala de Creencias de los Niños Sobre el Divorcio de los Padres (CBAPS). El propósito de este estudio fue examinar por primera vez la estructura factorial y las propiedades psicométricas de la Escala de Creencias de los Niños Sobre el Divorcio de los Padres (CBAPS) en una muestra comunitaria de niños hispanohablantes. Participaron 341 niños y adolescentes españoles de 10 a 17 años. El análisis de ítems y el análisis factorial exploratorio y confirmatorio sugirieron una versión abreviada de 18 ítems de la escala, manteniendo las seis subescalas de la medida original. La consistencia interna fue aceptable $(\alpha=.78)$ y la validez convergente se apoyó mediante la correlación entre la CBAPS y una medida de depresión. Se encontraron efectos de género y edad en las puntuaciones de la CBAPS. En general, la versión abreviada de la CBAPS obtenida mostró tener buenas propiedades psicométricas para su uso con niños y adolescentes españoles para evaluar creencias problemáticas con respecto al divorcio de sus padres.

Palabras clave: creencias problemáticas; divorcio parental; niños; adolescentes; depresión; evaluación

Divorce or separation of couples has become frequent. In Europe, the number of divorces has increased over recent decades: in 2016, the divorce rate per thousand inhabitants was more than double that of 1965 , with the number of divorces reaching almost one million in 2016 (Eurostat, 2019). Similarly, in Spain only in 2018 there were 4,098 separations and 95,254 divorces, of which over $42 \%$ of separated couples and $45 \%$ of divorced couples had one or

Received: January 15, 2020; accepted: February 04, 2020.

Corresponding author: Iván Fernández-Martínez, Miguel Hernández University, Department of Health Psychology, Avda. de la Universidad s/n, Elche 03202 (Alicante), Spain. E-mail: i.fernandez@umh.es; phone number: +34 96522 20 71; fax number: +34 966658904 more minor children (National Statistics Institute of Spain, 2019). This data highlights that many couples who divorce or separate have children who are involved in this process.

Extensive research indicates that parental divorce may constitute one of the most meaningful adversities that a child can experience during childhood, which often leads to substantial negative effects on children's functioning and development (e.g., Amato, 2010; DemirDagdas, Isik-Ercan, Intepe-Tingir, \& Cava-Tadik, 2017). Parental breakup negatively affects children's school performance and social skills and increases externalizing and internalizing problems (Amato \& Anthony, 2014; Anthony, DiPerna, \& Amato, 2014). Weaver and Schofield (2015) found that children from divorced families showed 
more internalizing and behavior problems compared with children from intact families. In addition, some research indicates that parental divorce's negative effects vary over time: divorce negatively affected children's anxiety, depression, sadness and self-esteem before and during the divorce, and negatively affected academic performance and social skills during and after the divorce (Kim, 2011; Strohschein, 2005). Other authors have found a negative association between the children's age at parental divorce and later depression in adulthood, suggesting that divorce can have long-term negative repercussions on the mental health of children of divorce and especially when it occurs at younger ages (Kravdal \& Grundy, 2019).

Moreover, a range of moderators and mediators govern divorce's effect on children (Weaver \& Schofield, 2015). Few studies have examined cognitive factors mediating children's adjustment to parental divorce (e.g., Kurdek, 1988); nonetheless, problematic beliefs have been supported as mediating divorce's effect on certain emotional problems (e.g., depression; DeLuciaWaack \& Gellman, 2007). Additionally, problematic beliefs about parental divorce appear correlated with children's maladjustment and the risk of developing psychopathological problems (Kurdek \& Berg, 1987; Ramírez, Botella, \& Carrobles, 1999). These findings suggest the importance of early detection and treatment of children's problematic beliefs about their parents' divorce.

The Children's Beliefs About Parental Divorce Scale (CBAPS; Kurdek \& Berg, 1987) appears to be the only reliable and validated instrument for examining children's problematic beliefs regarding their parents' divorce. The CBAPS showed good internal consistency and test-retest reliability in a sample of 170 American children and adolescents aged 6-17 years of age. The CBAPS contains six subscales that were created based on the clinical literature; however, testing conducted during the CBAPS' development research did not support a corresponding factor structure (Kurdek \& Berg, 1987). Nonetheless, the CBAPS remains the only available selfreport measure examining problematic beliefs about parental divorce; accordingly, clinicians and researchers use it frequently (e.g., Botha \& Wild, 2013).

A CBAPS translation targeting Spanish-speaking children is available (Ramírez et al., 1999); however, no research has examined its factor structure or psychometric properties. Following research arguing for the use of evidence-based instruments, this study (1) tested the Spanish CBAPS' factor structure, internal consistency, and convergent validity and (2) examined age and gender's association with problematic beliefs; this was conducted in a community sample of Spanish children and adolescents aged 10-17 years whose parents were divorced.

\section{Method}

\section{Participants}

Participants were 341 children and adolescents of divorced parents aged $10-17$ years $(M=13.57$ years; $S D=2.08 ; 152$ boys and 189 girls; $44.6 \%$ and $55.4 \%$, respectively). Most participants were Spanish; the remainder was from a range of Spanish-speaking countries. All participating families' socioeconomic status was middle-class (determined by the parents' employment status and the school's location). Most participants had one sibling (72.4\%); $18.8 \%$ had two; $4.4 \%$ had none; $2.6 \%$ had three; the remainder had four or more. Children with single mothers (i.e., who are raising their child alone without the father's presence and involvement) or one or both parents deceased were excluded. A subgroup containing 249 participants $(M=14.58$ years; $S D=1.611$; $56.3 \%$ girls $(n=142)$ was randomly selected to examine the convergent validity of the CBAPS.

\section{Instruments}

Children's Beliefs About Parental Divorce Scale (CBAPS; Kurdek \& Berg, 1987). The CBAPS is a 36-item measure examining children's beliefs about their parents' separation or divorce. The CBAPS includes the following subscales (six items each): (a) peer ridicule and avoidance: examines children's beliefs about how their parents' divorce causes their peers to avoid them and children's concern with being asked about their parents by their peers; (b) maternal blame: children's beliefs about their mother's entire responsibility for the divorce; (c) paternal blame: children's beliefs about their father's entire responsibility for the divorce; d) fear of abandonment: children's beliefs about the possible loss of the residential parent; (e) hope of reunification: belief that parental separation is temporary and reconciliation can be achieved through the child's actions; (f) self-blame: belief that parental separation is due to something the child said or did. The CBAPS is a dichotomous scale (i.e., responses are yes or no). Scores on each subscale are obtained by summing the number of problematic beliefs reported (i.e., maximum subscale score $=6$ ); similarly, the total score is calculated by summing the total number of problematic beliefs on all subscales (total maximum score $=36$ ). In the research that developed the CBAPS, its Cronbach's $\alpha$ was .80 for the total scale (Kurdek $\&$ Berg, 1987). The present study used the Spanish version (translated by Ramírez et al., 1999), without the new items that Ramírez et al. (1999) added to the original version.

Revised Children's Anxiety and Depression Scale (RCADS; Chorpita, Yim, Moffitt, Umemoto, \& Francis, 
2000). The RCADS is a self-report questionnaire containing 47 items in six subscales examining symptoms of separation anxiety disorder, social phobia, generalized anxiety disorder, panic disorder, obsessive compulsive disorder, and major depressive disorder. Responses to items used a 4-point Likert scale $(0=$ never, 3 =always). The cross-cultural reliability and usefulness of the RCADS has been supported (Piqueras, Martín-Vivar, Sandin, San Luis, \& Pineda, 2017). The Spanish version of the major depressive disorder (MDD) subscale was used to examine the CBAPS' convergent validity due to the relationship found between depressive symptoms and problematic beliefs in children of divorced or separated parents (e.g., DeLucia-Waack \& Gellman, 2007). Reliability for the RCADS depression subscale is good in the original version $(\alpha=.76$; Chorpita et al., $2000)$, the Spanish version $(\alpha=.79$; Sandín, Valiente, $\&$ Chorot, 2009) and our sample $(\alpha=.82)$.

\section{Procedure}

Participants were recruited from 15 public and private schools located in the southeast of Spain; schools were randomly selected from urban and rural areas in the interior and on the coast. Each school's principal gave permission to involve the school in the study. Parents signed informed consent forms; $95 \%$ of parents agreed to their children's participation. Instruments were anonymous and completed collectively in groups of 10 to 15 children at school and two researchers were present in each classroom. In order not to interrupt the school timetable and to avoid pulling the children out of class, the measures were completed in a single session held in the afternoon after school. After distributing the instruments, instructions were read aloud by researchers. The CBAPS contained the written instructions as in Kurdek and Berg (1987), thus indicating that items represented statements about children and their separated parents, the answer options (i.e., Yes or No) to be checked based on whether statements were true or not about how they think and feel about their parents' separation, and that there were no right or wrong answers. Children were asked to answer sincerely and the researchers resolved any uncertainties children had. The Ethics Committee of the authors' institution approved this study.

\section{Data analysis}

Factor analysis was used to examine the CBAPS's factor structure. First, confirmatory analysis (CFA) was performed on responses from the total sample. Due to the resulting model did not fit well with the subscales proposed by the original CBAPS' author, the dataset was randomly split into two groups, a training and a validation subgroup, as in previous studies (Orgilés, Owens, Espada, Piqueras, \& Carballo, 2013; Waumans et al., 2010). Exploratory factorial analysis (EFA) and confirmatory analysis (CFA) were performed on the training subgroup $(n=180)$ and validation subgroup $(n=161)$, respectively. The training and validation subgroups' mean ages were 13.46 years $(S D=2.12)$ and 13.69 years $(S D=2.05)$, respectively. Gender ratios were similar in both subgroups $(56 \%$ and $58 \%$ girls, respectively). The EFA matrix model's adequacy was tested using the Kaiser-Meyer-Olkin test (KMO) and Bartlett's test of sphericity. CFA was conducted using EQS to validate the structure obtained in EFA. Fit index values indicated good data fit: Root Mean Square Error of Approximation (RMSEA) $\leq .06$; Comparative Fit Index (CFI), Incremental Fit Index (IFI) and Goodnessof-Fit-Index $(\mathrm{GFI}) \geq .90$; and Standardized Root Mean square Residual (SRMR) <.08 (Bentler, 1990; Bollen, 1989; Hu \& Bentler, 1999; McDonald, 1999). Internal consistency was calculated using Cronbach's $\alpha$ for total and subscale scores. Pearson's correlation was calculated to analyze convergent validity. Gender and age effects were examined using a 2 (gender) x 4 (age) betweensubjects analysis of variance (ANOVA).

\section{Results}

\section{Factor analysis}

Statistical analysis of items was conducted for the total sample $(N=341)$, obtaining each item's mean score, standard deviation and discrimination index value using item-scale correlation. Corrected correlation coefficients $>.25$ were considered acceptable (Nunnally \& Bernstein, 1995). The results suggested eliminating 18 items due to low item-scale correlation and very different mean scores from the remaining items (i.e., items $1,2,3,4,5$, $6,9,11,14,15,16,17,19,20,24,30,31$, and 34). The KMO index value (.72) and Bartlett's test of sphericity $\left(\chi^{2}=2052.97 ; p<.001\right)$ indicated adequacy to conduct EFA on the retained 18 items. Six factors were extracted from the training subgroup's scores $(n=180)$, explaining $62.28 \%$ of variance.

CFA was conducted on the validation subgroup $(n=161)$, to test the resulting factor structure. Maximum likelihood estimation was used; the results indicted good data fit $($ RMSEA $=.038(.009-.057) ; \mathrm{CFI}=.93 ; \mathrm{IFI}=.93$; SRMR $=.08 ; \mathrm{GFI}=.90)$. Standardized factor coefficients are shown in Table 1; all were statistically significant with values exceeding .35, except regarding item 18 . 
Table 1. Results of confirmatory factor analysis

\begin{tabular}{|c|c|c|c|c|c|c|}
\hline \multirow[b]{2}{*}{ Items } & \multicolumn{6}{|c|}{ Factor loading } \\
\hline & $\mathrm{F} 1$ & F2 & F3 & $\mathrm{F} 4$ & F5 & F6 \\
\hline \multicolumn{7}{|l|}{ Peer ridicule and avoidance } \\
\hline 7. I like talking to my friends as much now as I used to & 662 & - & - & - & - & - \\
\hline 13. I like playing with my friends as much now as I used to & 436 & - & - & - & - & - \\
\hline 25. My friends and I do many things together & 692 & - & - & - & - & - \\
\hline \multicolumn{7}{|l|}{ Paternal blame } \\
\hline 8. My father is usually a nice person & - & .636 & - & - & - & - \\
\hline 26. There are a lot of things about my father I like & - & .742 & - & - & - & - \\
\hline 32. My father is more good than bad & - & .705 & - & - & - & - \\
\hline \multicolumn{7}{|l|}{ Fear of abandonment } \\
\hline 27. I sometimes think that one day I may have to go live with a friend or relative & - & - & .425 & - & - & - \\
\hline 21. I feel that my parents still love me & - & - & 684 & - & - & - \\
\hline 33. I feel my parents still like me & - & - & .634 & - & - & - \\
\hline \multicolumn{7}{|l|}{ Maternal blame } \\
\hline 22. My mother caused most of the trouble in my family & - & - & - & .557 & - & - \\
\hline 10. My mother is usually a nice person & - & - & - & .542 & - & - \\
\hline 28. My mother is more good than bad & - & - & - & .359 & - & - \\
\hline \multicolumn{7}{|l|}{ Hope of reunification } \\
\hline $\begin{array}{l}\text { 23. My parents will probably see that they have made a mistake and get back together } \\
\text { again }\end{array}$ & - & - & - & - & .948 & - \\
\hline 29. I sometimes think that my parents will one day live together again & - & - & - & - & .634 & - \\
\hline $\begin{array}{l}\text { 35. I sometimes think that once my parents realize how much I want them to, they'll } \\
\text { live together again }\end{array}$ & - & - & - & - & .504 & - \\
\hline \multicolumn{7}{|l|}{ Self-blame } \\
\hline 12. My parents would probably be happier if I were never born & - & - & - & - & - & .931 \\
\hline 18. My parents probably argue more when I'm with them than when I'm gone & - & - & - & - & - & .214 \\
\hline 36. My parents would probably still be living together if it weren't for me & - & - & - & - & - & .774 \\
\hline
\end{tabular}

\section{Descriptive data}

Means and standard deviations for scores on the total scale and each subscale were calculated using the entire sample (Table 2). The mean score was 0.14 ( 0.16 for boys and 0.17 for girls). Gender affected mean score regarding total beliefs $(d=0.11)$, paternal blame $(d=0.38)$, maternal blame $(d=0.29)$, and hope of reunification $(d=0.19$; all $p \mathrm{~s}<.05)$; girls reported more problematic beliefs except regarding hope of reunification. Age affected mean scores only regarding hope of reunification and self-blame (beliefs decreased with age; $p<.05)$. Gender and age did not significantly interact.

\section{Reliability and convergent validity}

Internal consistency was estimated in the entire sample $(N=341)$. The scale demonstrated acceptable internal consistency (Cronbach's $\alpha=.78$ ), indicating that all items measured the same construct (Table 3). Subscales' reliability was adequate $(\alpha=.62$ for peer ridicule and avoidance; $\alpha=.73$ for paternal blame; $\alpha=.73$ for hope of reunification, and $\alpha=.63$ for self-blame), except for the fear of abandonment $(\alpha=.58)$ and maternal blame $(\alpha=.59)$ subscales. Convergent validity was calculated through correlation between CBAPS and RCADS scores in a subgroup containing 249 participants. A low but significant correlation was found between CBAPS 
Table 2. Mean and standard deviation by gender and age

\begin{tabular}{|c|c|c|c|c|c|c|}
\hline & \multicolumn{5}{|c|}{ Age } & \multirow{3}{*}{ Effects } \\
\hline & $10-11$ & $12-13$ & $14-15$ & $16-17$ & Total & \\
\hline & $M(\mathrm{SD})$ & $M(\mathrm{SD})$ & $M(\mathrm{SD})$ & $M(\mathrm{SD})$ & $M(\mathrm{SD})$ & \\
\hline \multicolumn{7}{|c|}{ Peer ridicule and avoidance } \\
\hline Boys & $.18(.27)$ & $.13(.28)$ & $.05(.16)$ & $.13(.25)$ & $.11(.24)$ & \multirow{3}{*}{$\begin{array}{l}\text { Gender: } F(1.161)=.065 p=.800 \\
\text { Age: } F(3.161)=2.08 p=0.105 \\
\text { Gender X Age }=F(3,161)=0.60 p=0.981\end{array}$} \\
\hline Girls & $.17(.28)$ & $.14(.27)$ & $.03(.10)$ & $.11(.24)$ & $.11(.24)$ & \\
\hline Total & $.17(.28)$ & $.14(.28)$ & $.04(.13)$ & $.12(.25)$ & $.11(.24)$ & \\
\hline \multicolumn{7}{|c|}{ Paternal blame } \\
\hline Boys & $.06(.13)$ & $.22(.30)$ & $.09(.23)$ & $.15(.33)$ & $.14(.27)$ & \multirow{3}{*}{$\begin{array}{l}\text { Gender: } F(1,161)=6.89 p<0.01 \\
\text { Age: } F(3,161)=0.346 p=0.792 \\
\text { Gender } X \text { Age }=F(3,161)=1.29 p=0.278\end{array}$} \\
\hline Girls & $.37(.41)$ & $.24(.34)$ & $.25(.34)$ & $.21(.35)$ & $.26(.35)$ & \\
\hline Total & $.22(.27)$ & $.23(.32)$ & $.17(.29)$ & $.18(.34)$ & $.21(.33)$ & \\
\hline \multicolumn{7}{|c|}{ Fear of abandonment } \\
\hline Boys & $.18(.23)$ & $.30(.39)$ & $.06(.17)$ & $.13(.20)$ & $.16(.27)$ & \multirow{3}{*}{$\begin{array}{l}\text { Gender: } F(1,161)=0.03 p=0.954 \\
\text { Age: } F(3,161)=0.209 p=0.103 \\
\text { Gender } X \text { Age }=F(3,161)=1.157 p=0.328\end{array}$} \\
\hline Girls & $.19(.33)$ & $.19(.31)$ & $.17(.23)$ & $.12(.19)$ & $.17(.27)$ & \\
\hline Total & $.18(.28)$ & $.24(.35)$ & $.11(.20)$ & $.13(.20)$ & $.16(.27)$ & \\
\hline \multicolumn{7}{|c|}{ Maternal blame } \\
\hline Boys & $.09(.22)$ & $.09(.19)$ & $.06(.20)$ & $.07(.21)$ & $.07(.20)$ & \multirow{3}{*}{$\begin{array}{l}\text { Gender: } F(1.161)=2.25 p<0.05 \\
\text { Age: } F=(3,161)=0.527 p=0.664 \\
\text { Gender } X \text { Age }=F(3,161)=0.065 p=0.978\end{array}$} \\
\hline Girls & $.15(.22)$ & $.17(.27)$ & $.10(.19)$ & $.11(.19)$ & $.13(.22)$ & \\
\hline Total & $.12(.21)$ & $.24(.35)$ & $.08(.19)$ & $.09(.20)$ & $.11(.21)$ & \\
\hline \multicolumn{7}{|c|}{ Hope of reunification } \\
\hline Boys & $.48(.38)$ & $.28(.42)$ & $.11(.24)$ & $.12(.25)$ & $.21(.34)$ & \multirow{3}{*}{$\begin{array}{l}\text { Gender: } F(1.161)=4.34 \mathrm{p}<0.05 \\
\text { Age: } F=(3.161)=4.83 \mathrm{p}<0.01 \\
\text { Gender } X \text { Age }=F(3,161)=1.81 \mathrm{p}=0.148\end{array}$} \\
\hline Girls & $.17(.21)$ & $.22(.36)$ & $.10(.27)$ & $.09(.21)$ & $.15(.28)$ & \\
\hline Total & $.33(.29)$ & $.25(.39)$ & $.10(.25)$ & $.10(.23)$ & $.18(.31)$ & \\
\hline \multicolumn{7}{|c|}{ Self-blame } \\
\hline Boys & $.18(.31)$ & $.22(.26)$ & $.05(.12)$ & $.12(.20)$ & $.13(.22)$ & \multirow{3}{*}{$\begin{array}{l}\text { Gender: } F(1.161)=1.37 \mathrm{p}=0.242 \\
\text { Age: } F=(3.161)=2.83 \mathrm{p}<0.05 \\
\text { Gender } X \text { Age }=F(4.161)=0.112 \mathrm{p}=0.253\end{array}$} \\
\hline Girls & $.24(.34)$ & $.27(.37)$ & $.13(.25)$ & $.14(.27)$ & $.20(.31)$ & \\
\hline Total & $.21(.33)$ & $.24(.31)$ & $.09(.18)$ & $.13(.23)$ & $.17(.28)$ & \\
\hline \multicolumn{7}{|c|}{ Total score } \\
\hline Boys & $.20(.26)$ & $.21(.31)$ & $.07(.18)$ & $.12(.24)$ & $.14(.26)$ & \multirow{3}{*}{$\begin{array}{l}\text { Gender: } F(6,161)=2.593 p<0.05 \\
\text { Age: } F=(18,161)=1.371 p=0.141 \\
\text { Gender X Age }=F(18,161)=0.76 p=0.742\end{array}$} \\
\hline Girls & $.21(.30)$ & $.21(.32)$ & $.13(.23)$ & $.13(.24)$ & $.17(.28)$ & \\
\hline Total & $.20(.28)$ & $.21(.31)$ & $.10(.21)$ & $.12(.24)$ & $.16(.27)$ & \\
\hline
\end{tabular}

total score and the depression subscale of the RCADS $(r=0.25 ; p<.01)$. Intercorrelations between CBAPS subscales were also calculated (Table 4); the strongest significant correlations were found between fear of abandonment and self-blame $(r=.53)$ and between fear of abandonment and maternal blame $(r=.47)$.

\section{Discussion}

This study examined the CBAPS' factor structure and reliability in a community sample of Spanish children
Table 3. Cronbach's alpha coefficients

\begin{tabular}{llll}
\hline & Boys & Girls & Total \\
\hline Peer ridicule and avoidance & .63 & .63 & .62 \\
Paternal blame & .72 & .73 & .73 \\
Fear of abandonment & .59 & .56 & .58 \\
Maternal blame & .59 & .58 & .59 \\
Hope of reunification & .77 & .70 & .73 \\
Self-blame & .58 & .69 & .63 \\
Total score & .74 & .80 & .78 \\
\hline
\end{tabular}


Table 4. Correlations among subscales

\begin{tabular}{lccccc}
\hline & PR & PB & FA & MB & HR \\
\hline Peer ridicule and avoidance & - & & & & \\
Paternal blame & $0.19^{*}$ & - & & & \\
Fear of abandonment & $0.31^{* *}$ & $0.38^{* *}$ & - & & \\
Maternal blame & $0.28^{* *}$ & $0.24^{* *}$ & $0.47^{* *}$ & - & - \\
Hope of reunification & 0.12 & 0.10 & $0.26^{* *}$ & 0.10 & $0.26^{* *}$ \\
Self-blame & $0.22^{* *}$ & $0.16^{*}$ & $0.53^{* *}$ & $0.42^{* *}$ & $0.60 \%$ \\
\hline
\end{tabular}

Note. PR: Peer ridicule and avoidance, PB: Paternal blame, FA: Fear of abandonment; MB: Maternal blame, HR: Hope of reunification.

* Correlations significant at $p<.05 ; * *$ Correlations significant at $p<.01$

and adolescents aged 10-17 years. The results suggested using a shortened version of the scale; EFA and CFA both supported the same six-factor structure proposed by the CBAPS' authors, but including only 18 items. No research has analyzed the CBAPS' factorial structure in other countries; therefore, the present results may only be compared with those obtained regarding the original CBAPS. The CBAPS was created based on a 52 -item projective test; 36 items were selected from 70 reviewed items and grouped into six belief domains following the clinical literature; included items were adapted to use dichotomous responses. In the original research, EFA did not support the proposed six-factor structure: fear of abandonment and self-blame did not emerge as separate factors. Nonetheless, the authors retained the self-blame subscale for clinical interest and because scores on its items clustered together (Kurdek \& Berg, 1987). In the present research, eighteen items were eliminated from the Spanish CBAPS; some of these (e.g., items 1 and 24) were also problematic in the original version, indicating that they did not examine the intended beliefs, despite their clinical interest. The reduced number of items in the proposed Spanish short version allows the scale to examine the same factors in less time. All items included in the proposed Spanish version had factor load values $>.35$, except item 18 (my parents probably argue more when I'm with them than when I'm gone). This item's load was close to the acceptance value (.25; Nunnally \& Bernstein, 1995) and the item did not present secondary saturations; therefore, it was considered that the SelfBlame factor was better represented without removing it. Future research should examine this item's low factor load.

Internal consistency $(\alpha=.78)$ for the Spanish data is similar to the coefficient obtained for the original version $(\alpha=.80)$, although it includes 18 more items than the Spanish version. Reliability was also adequate for each subscale with coefficients ranging from .62 to .73 , except for fear of abandonment and maternal blame subscales (alpha values near .60). The fact that each subscale includes only three items may explain these results, but further research should be done to examine this issue. Nonetheless, all items were decided to be in keeping considering its clinical interest (Kurdek \& Berg, 1987). The strongest correlation among the CBAPS subscales was found between fear of abandonment and self-blame, similar to the original version of the scale. These results support the CBAPS' authors' suggestion that items from both subscales appear to belong to a common factor connected with parental acceptance (Kurdek \& Berg, 1987). Other research has found that beliefs regarding fear of abandonment and self-blame are positively related to anxious and depressive symptoms, and that both variables may predict parentification in children exposed to marital conflict (Doucet \& Fortin, 2010; Jouriles, Collazos, Stephens, McDonald, \& Swank, 2000). However, to our knowledge, no other studies have examined the relationship between problematic beliefs measured by the CBAPS (e.g., their frequency and cooccurrence); future research should therefore address this topic. Convergent validity was examined using correlation between the total score of the CBAPS and a measure of depression; a weak but significant correlation was found, indicating acceptable convergent validity. This finding extends previous research suggesting the relationship among problematic beliefs and depressive symptoms in children of divorce (DeLucia-Waack \& Gellman, 2007).

Girls reported more problematic beliefs regarding paternal and maternal blame, whereas boys reported more problematic beliefs regarding hope of reunification. These results diverge from those reported in the CBAPS' original development study (Kurdek \& Berg, 1987) and the research that translated the CBAPS into Spanish (Ramírez et al., 1999), neither of which detected any effect of gender on scores. A more recent study used 
the CBPAS to examine 134 schoolchildren aged 5-10 years; it detected marginally higher scores among girls than boys (DeLucia-Waack \& Gellman, 2007). The present gender effect was significant; however, it was small, and should therefore be interpreted cautiously. Previous research examining gender's moderation of divorce's effects has yielded contradictory results: some authors have found more problems among children and adolescents of one gender (e.g., Oldehinkel, Ormel, Veenstra, De Winter, \& Verhulst, 2008); others found no differences between girls and boys (e.g. Strohschein, 2005; Van Gils, Janssens, \& Rosmalen, 2014). In this study, beliefs regarding hope of reunification and selfblame varied by age, generally decreasing among older children, supporting Kurdek and Berg's (1987) finding that parental divorce affects children more strongly that adolescents. Younger children's thoughts tend to be more egocentric, promoting beliefs of responsibility for others' behavior. Children may believe that, as they consider themselves the cause of their parental divorce, they are also able to reunify them; however, this belief's causes remain unclear.

This study has the following limitations to consider. First, data were collected using self-report measures; it would have been desirable to include a measure that collected information from parents and test for correlation between scores on both measures. Second, the sample was small and from a single region of Spain, which should be addressed in future studies with the Spanish CBAPS. Third, the lack of studies examining the CBAPS' psychometric properties prevented comparison of the present findings with data collected in countries other than Spain. Additionally, future research should examine other psychometric properties of the scale that were not analyzed in the current study (e.g., test-retest reliability, factorial invariance).

Nonetheless, despite the limitations mentioned above, the Spanish CBAPS is presently the only Spanish-language self-report measure examining children's problematic beliefs about parental divorce. This research indicates that it has good psychometric properties and an acceptable factor structure, suggesting support for its clinical use in the therapeutic process with Spanish-speaking children and for research purposes. Furthermore, in this study an 18-item shortened version of the CBAPS has been obtained, maintaining the same six subscales as the original measure. Although the stability of this shortened version of the CBAPS should be examined in further studies with other samples, it allows the scale to be applied in a reduced time compared to the long version, making it a more time-efficient tool. Also, having an instrument such as CBAPS can be of great interest, considering the negative repercussions that divorce or separation of parents can have on their children in different domains (e.g., social, academic, family, emotional, behavioral) (see Demir-Dagdas et al., 2017) and especially previous research suggesting that problematic beliefs about parental divorce may affect psychological problems in childhood, such as depressive symptoms (DeLucia-Waack \& Gellman, 2007). Therefore, assessing and detecting children's dysfunctional beliefs about parental divorce would importantly facilitate early and effective intervention.

\section{Conflict of interest}

The authors declare that they have no conflict of interest.

\section{References}

Amato, P. R. (2010). Research on divorce: Continuing trends and new developments. Journal of Marriage and Family, 72, 650666. https://doi.org/10.1111/j.1741-3737.2010.00723.x

Amato, P. R., \& Anthony, C. J. (2014). Estimating the effects of parental divorce and death with fixed effects models. Journal of Marriage and Family, 76, 370-386. https://doi.org/10.1111/ jomf. 12100

Anthony, C. J., DiPerna, J. C., \& Amato, P. R. (2014). Divorce, approaches to learning, and children's academic achievement: A longitudinal analysis of mediated and moderated effects. Journal of School Psychology, 52, 249-261. https://doi. org/10.1016/j.jsp.2014.03.003

Bentler, P. M. (1990). Comparative fit indexes in structural models. Psychological Bulletin, 107, 238-246.

Bollen, K. A. (1989). Structural equations with latent variables. John Wiley and Sons.

Botha, C. J., \& Wild, L. G. (2013). Evaluation of a school-based intervention programme for South African children of divorce. Journal of Child \& Adolescent Mental Health, 25, 81-91. https://doi.org/10.2989/17280583.2013.768528

Chorpita, B. F., Yim, L., Moffitt, C. E., Umemoto, L. A., \& Francis, S. E. (2000). Assessment of symptoms of DSM-IV anxiety and depression in children: A revised child anxiety and depression scale. Behavior Research and Therapy, 38 , 835-855. https://doi.org/10.1016/s0005-7967(99)00130-8

DeLucia-Waack, J. L., \& Gellman, R. A. (2007). The efficacy of using music in children of divorce groups: Impact on anxiety, depression, and irrational beliefs about divorce. Group Dynamics: Theory, Research, and Practice, 11, 272-282. https://doi.org/10.1037/1089-2699.11.4.272

Demir-Dagdas, T., Isik-Ercan, Z., Intepe-Tingir, S., \& CavaTadik, Y. (2017). Parental divorce and children from diverse backgrounds: multidisciplinary perspectives on mental health, parent-child relationships, and educational experiences. Journal of Divorce \& Remarriage, 59, 469-485. https://doi.or $\mathrm{g} / 10.1080 / 10502556.2017 .1403821$

Doucet, M., \& Fortin, A. (2010). La parentification et les conflits de loyauté chez l'enfant exposé à la violence conjugale: Contribution du point de vue de l'enfant sur la violence [Parentification and 
loyalty conflicts in children exposed to domestic violence: Contribution of children's appraisal of violence]. Enfance, 62, 201-221. https://doi.org/10.4074/S0013754510002041

Eurostat (2019). Eurostat Statistics Explained. Marriage and divorce statistics. https:/ec.europa.eu/eurostat/statisticsexplained/index.php/Marriage_and_divorce_statistics

Hu, L., \& Bentler, P. (1999). Cutoff criteria for fit indexes in covariance structure analysis: Conventional criteria versus new alternatives. Structural Equation Modeling, 6, 1-55. https://doi.org/10.1080/10705519909540118

Jouriles, E. N., Collazos, L., Stephens, N., McDonald, R., \& Swank, P. (2000). Variability in adjustment of children of battered women: The role of child appraisals of interparent conflict. Cognitive Therapy and Research, 24, 233-249. https://doi.org/10.1023/A:1005402310180

Kim, H. S. (2011). Consequences of parental divorce for child development. American Sociological Review, 76, 487-511. https://doi.org/10.1177/0003122411407748

Kravdal, Ø., \& Grundy, E. (2019). Children's age at parental divorce and depression in early and mid-adulthood. Population Studies, 73, 37-56. https://doi.org/10.1080/00324728.2018.15 49747

Kurdek, L. A. (1988). Cognitive mediators of children's adjustment to divorce. In S. A. Wolchik \& P. Karoly (Eds.), Children of divorce: Empirical perspectives on adjustment (pp. 233-264). Gardner Press.

Kurdek, L. A., \& Berg, B. (1987). Children's Beliefs About Parental Divorce Scale: Psychometric characteristics and concurrent validity. Journal of Consulting and Clinical Psychology, 5, 712-718. https://doi.org/10.1037//0022-006x.55. 5.712

McDonald, R. P. (1999). Test theory. A unified treatment. Lawrence Erlbaum Associates.

National Statistics Institute of Spain. (2019). Statistics on Annulments, Separations and Divorces. Year 2018. https:// www.ine.es/dyngs/INEbase/es/operacion. $\mathrm{htm} ? \mathrm{c}=$ Estadistica_C\&cid $=1254736176798 \& \mathrm{menu}=$ resultados\&idp $=1254735573206$

Nunally, J. C., \& Bernstein, I. J. (1995). Teoría psicométrica [Psychometric theory]. McGraw-Hill.
Oldehinkel, A. J., Ormel, J., Veenstra, R., De Winter, A. F., \& Verhulst, F. C. (2008). Parental divorce and offspring depressive symptoms: Dutch developmental trends during early adolescence. Journal of Marriage and Family, 70, 284293. https://doi.org/10.1111/j.1741-3737.2008.00481.X

Orgilés, M., Owens, J., Espada, J. P., Piqueras, J. A., \& Carballo, J. L. (2013). Spanish version of the Sleep Self-Report (SSR): factorial structure and psychometric properties. Child: Care, Health and Development, 39, 288-95. https://doi.org/10.1111/ j.1365-2214.2012.01389.x

Piqueras, J. A., Martín-Vivar, M., Sandín, B., San Luis, C., \& Pineda, D. (2017). The Revised Child Anxiety and Depression Scale: A systematic review and reliability generalization meta-analysis. Journal of Affective Disorders, 218, 153-169. https://doi.org/10.1016/j.jad.2017.04.022

Ramírez, M., Botella, J. y Carrobles, J. A. (1999). Creencias infantiles sobre la separación parental [Children's beliefs about parental separation]. Psicología Conductual, 7, 49-73.

Sandín, B., Valiente, R. M. y Chorot, P. (2009). RCADS: Evaluación de los síntomas de los trastornos de ansiedad y depresión en niños y adolescentes [RCADS: Assessment of anxiety and depressive disorder symptoms in children and adolescents]. Revista de Psicopatología y Psicología Clínica, 14, 193-206. https://doi.org/10.5944/rppc.vol.14.num.3.2009.4078

Strohschein, L. (2005). Parental divorce and child mental health trajectories. Journal of Marriage and Family, 67, 1286-1300. https://doi.org/10.1111/j.1741-3737.2005.00217.x

Van Gils, A., Janssens, K. A. M., \& Rosmalen, J. G. M. (2014). Family Disruption Increases Functional Somatic Symptoms in Late Adolescence: The TRAILS Study. Health Psychology, 33, 1354-1361. https://doi.org/10.1037/hea0000073

Waumans, R. C., Terwee, C. B., Van den Berg, G., Knol, D. L., Van Litsenburg, R. R., \& Gemke, R. J. (2010). Sleep and sleep disturbance in children: reliability and validity of the Dutch version of the Child Sleep Habits Questionnaire. Sleep, 33, 841-845. https://doi.org/10.1093/sleep/33.6.841

Weaver, J. M., \& Schofield, T. J. (2015). Mediation and moderation of divorce effects on children's behavior problems. Journal of Family Psychology, 29, 39-48. https://doi.org/10.1037/fam000 0043 